January 2006

\title{
Relationship between antipyretic effects and cytokine levels in uncomplicated falciparum malaria during different treatment regimes
}

Elisabeth Hugosson

Karolinska University Hospital

Scott M. Montgomery

Karolinska University Hospital

Zul Premji

Aga Khan University, zul.premji@aku.edu

Marita Troye-Blomberg

Stockholm University

Anders Bjorkman

Karolinska University Hospital

Follow this and additional works at: http://ecommons.aku.edu/eastafrica_fhs_mc_pathol

Part of the Pathology Commons

\section{Recommended Citation}

Hugosson, E., Montgomery, S. M., Premji, Z., Troye-Blomberg, M., Bjorkman, A. (2006). Relationship between antipyretic effects and cytokine levels in uncomplicated falciparum malaria during different treatment regimes. Acta Tropica, 99(1), 75-82.

Available at: http://ecommons.aku.edu/eastafrica_fhs_mc_pathol/71 


\title{
Relationship between antipyretic effects and cytokine levels in uncomplicated falciparum malaria during different treatment regimes
}

\author{
Elisabeth Hugosson ${ }^{\mathrm{a}, \mathrm{e}, *}$, Scott M. Montgomery ${ }^{\mathrm{b}, \mathrm{c}}$, Zul Premji ${ }^{\mathrm{d}}$, \\ Marita Troye-Blomberg ${ }^{\mathrm{e}}$, Anders Björkman ${ }^{\mathrm{a}}$ \\ a Malaria Research Unit (M9), Division of Infectious Diseases, Department of Medicine, \\ Karolinska University Hospital, 17176 Stockholm, Sweden \\ ${ }^{\mathrm{b}}$ Clinical Epidemiology Unit, Department of Medicine, Karolinska University Hospital, Karolinska Institutet, 17176 Stockholm, Sweden \\ ${ }^{\mathrm{c}}$ Kliniskt forskningscentrum, Universitetssjukhuset, 70116 Örebro, Sweden \\ ${ }^{\mathrm{d}}$ Department of Parasitology/Medical Entomology, Muhimbili University College of Health Sciences, \\ Dar es Salaam, United Republic of Tanzania \\ e Department of Immunology, Stockholm University, Arrheniuslaboratorierna, F5, 10691 Stockholm, Sweden
}

Received 20 January 2006; received in revised form 26 July 2006; accepted 27 July 2006

Available online 8 September 2006

\begin{abstract}
We have previously shown that both chloroquine and paracetamol (acetaminophen) have antipyretic activity during treatment of acute uncomplicated Plasmodium falciparum malaria in children 1-4 years old. Here, we studied if this effect was accompanied by changes in plasma cytokine levels.

The 104 children were treated with either chloroquine or sulfadoxine/pyrimethamine (SP) alone, SP + chloroquine or $\mathrm{SP}+$ paracetamol for 4 days. Cytokine levels were determined days 0,2 and 3 , body temperature every sixth hour until $72 \mathrm{~h}$ and parasitemia once daily for 4 days.

At admission, body temperature correlated with levels of IL-10, IFN- $\gamma$ and IL-6, and parasitemia correlated with IL-10 and IL-6. Except for TNF- $\alpha$ and IL-1 $\beta$, where no significant effect was found, all cytokine levels (IL-10, IFN- $\gamma$, IL-6, IL-12, IL-13, IL-18 and IL-4) decreased up to day $2(p<0.05)$. IL-6 levels continued to fall from days 2 to $3(p<0.05)$, whereas increased levels were found for several cytokines (IL-12, IL-13, IL-18 and IL-1 $\beta)(p<0.05)$.

The antipyretic effects of chloroquine and paracetamol could not be related to any specific changes in the evaluated cytokine production or in Th1/Th2 or inflammatory/anti-inflammatory cytokine ratios. Alternative mechanisms for antipyretic effects and associations between fever and cytokine levels during uncomplicated $P$. falciparum malaria are therefore discussed.
\end{abstract}

(C) 2006 Elsevier B.V. All rights reserved.

Keywords: Plasmodium falciparum malaria; Chloroquine; Sulfadoxine-pyrimethamine; Paracetamol; Antipyretics; Cytokines

\footnotetext{
* Corresponding author. Tel.: +46 8 4299122/51776739/164168; fax: +46851776740 .

E-mail addresses: ehugosson@hotmail.com (E. Hugosson), Scott.Montgomery@ki.se (S.M. Montgomery), zpremji@muchs.ac.tz (Z. Premji), marita@imun.su.se (M. Troye-Blomberg), anders.bjorkman@karolinska.se (A. Björkman).
}

\section{Introduction}

Fever is the most common indicator of disease in human malaria, but the mechanisms for its induction and regulation during the disease is not clear. From studies with the bacterial product LPS, it has for many years 
been thought that fever is induced via the intermediate production of pyrogenic cytokines (IL-1, TNF- $\alpha$, IL-6, IL-8, MIP-1 $\beta$, and IFN- $\gamma$ ) and that the height and magnitude of fever is a sum of the interactions of pyrogenic cytokines and endogenous antipyretics (IL-10, AVP and glucocorticoids) (Leon, 2002). However, the concept is challenged by findings indicating that fever during infection can occur independently of cytokine production (Dinarello, 2004). Toll-like receptor (TLR) signal transduction provides an explanation by which microbial products can cause fever directly on the vascular network supplying the thermoregulatory centre in the anterior hypothalamus. Thus, fever during an infection is now thought to be a result of both cytokine and TLRs (or other receptors) ligand activity, followed by cyclooxygenase2, prostaglandin $\mathrm{E}_{2}\left(\mathrm{PGE}_{2}\right)$ production and activation of hypothalamic $\mathrm{PGE}_{2}$ receptors.

There are several relations that indicate a pivotal role for pro-inflammatory cytokines in induction of malarial fever. Malaria parasite derived glycosylphosphatidylinositol (GPI) induces TNF and IL-1 in macrophages and causes pyrexia in mice models (Schofield and Hackett, 1993). Elevated plasma levels of TNF, IL-6 and IFN- $\gamma$ are detected during uncomplicated Plasmodium falciparum malaria compared to asymptomatic infections (Mshana et al., 1991; Anstey et al., 1996; Othoro et al., 1999). For the cytokines IL-1 $\beta$, IL-4, IL-12, IL13 and IL-18 the information is less clear, or so far missing (Mshana et al., 1991; Othoro et al., 1999; Chaisavaneeyakorn et al., 2003). Plasmodium vivax fever episodes appear with $48 \mathrm{~h}$ intervals coinciding with increased serum levels of TNF (Karunaweera et al., 1992). In human cerebral malaria, fever was reduced by injection of anti-TNF antibodies (Kwiatkowski et al., 1993). This does however not exclude the possibility that at least a part of the fever induction in non-complicated $P$. falciparum malaria is cytokine independent.

We have previously shown that the antimalarial drug chloroquine exerts antipyretic effects, equal to paracetamol, during treatment of uncomplicated $P$. falciparum malaria (Hugosson et al., 2003). Chloroquine inhibits production of several pro-inflammatory cytokines and enhances IL-10 production in human in vitro assays (Hugosson et al., 2002; Picot et al., 1993; Ertel et al., 1991; Landewe et al., 1992; van den Borne et al., 1997; Karres et al., 1998; Jeong and Jue, 1997). The protection of rats challenged by lethal doses of CpG and LPS by chloroquine treatment is associated with decreases in serum levels of TNF- $\alpha$ and IL-6 (Hong et al., 2004). It is therefore reasonable to believe that chloroquine could inhibit malarial fever by altering the levels and the balance of the cytokine response during malaria infections.
However, recent evidence suggests that chloroquine can block signalling via TLRs (Lee et al., 2003; Zou et al., 2003), which provides a possible mechanism for a cytokine independent mechanism for the antipyretic activity of chloroquine.

In order to study the role of pro- and anti-inflammatory cytokines in relation to fever and in chloroquine induced antipyresis, we compared cytokine levels before and during treatment of acute uncomplicated $P$. falciparum malaria. We investigated differences between four drug regimes generating different effects on the body temperature.

\section{Methods}

\subsection{Study area}

The study was carried out in Kibaha District Hospital $40 \mathrm{~km}$ north-west of Dar es Salaam, Tanzania, an area holoendemic for malaria with largely perennial transmission of mainly $P$. falciparum.

\subsection{Study patients}

Data and samples in this work are obtained from patients included in a study designed to compare antipyretic, parasitological and immunulogical effects of four different antimalarial treatment regimes (Hugosson et al., 2003). Children between 12 and 59 months of age attending the primary health care unit of the hospital, between 3 July and 20 August 1998, were included in the study, if they fulfilled the inclusion criteria of uncomplicated mono-infection with $P$. falciparum (2000-250 000 parasites/mL, axillary temperature 37.5$40.0^{\circ} \mathrm{C}$ ). Children were not considered for the study if they had altered level of consciousness, convulsions, prostration, circulatory shock or respiratory distress, hyperparasitemia ( $>250000$ parasites $/ \mu \mathrm{L}$ ), severe anaemia (haemoglobin levels below $5.0 \mathrm{~g} / \mathrm{dL}$ ) or suspected coexisting diseases. The guardians of the children, were asked for their informed consent before the children were enrolled in the study. Ethical clearance was provided by the Ministry of Health, Tanzania and by clinical research committee of the Karolinska Institutet, Stockholm, Sweden. A more detailed information about the patients is provided in a previous report (Hugosson et al., 2003).

\subsection{Drug administration}

At admission to the hospital, the patients were consecutively divided into either of four treatment 
groups, according to a predetermined schedule: (1) chloroquine alone, (2) sulfadoxine/pyrimethamine (SP) alone, (3) SP + chloroquine, and (4) SP + paracetamol. The three drugs were given as follows: (a) chloroquine phosphate (F Hoffman-La Roche, Basel, Switzerland) $10+10+5 \mathrm{mg}$ base $/ \mathrm{kg}$ body weight $(\mathrm{BW})$ over a period of 3 days, (b) SP (Fansidar $^{\circledR}$, F HoffmanLa Roche, Basel, Switzerland) single dose of $1.25 \mathrm{mg}$ pyrimethamine and $25 \mathrm{mg}$ sulfadoxine $/ \mathrm{kg} \mathrm{BW}$, and (c) paracetamol, $15 \mathrm{mg} / \mathrm{kg}$ BW every 8 for $72 \mathrm{~h}$. All treatments started at 3-4 p.m. on the day of admission and were given under close supervision by the research team. No antipyretic drugs were given to the children apart from the treatment schedule defined above. Mechanical antipyresis (tepid sponging and electric fanning) was to be considered during episodes of high fever $\left(>39^{\circ} \mathrm{C}\right)$.

\subsection{Sample collection and microscopy}

Venous blood samples were taken on day 0 (before start of treatment $)\left(=T_{0}\right)$ and on day $2\left(=T_{2}\right)$ and $3\left(=T_{3}\right)$, respectively. After centrifugation, the plasma was immediately aliquoted and stored at $-30^{\circ} \mathrm{C}$ during the time of the study (at the most 2 months) and thereafter at $-70^{\circ} \mathrm{C}$ until transferred on dry ice before being finally stored at $-70{ }^{\circ} \mathrm{C}$ until analysed year 2000 . Axillary body temperature was measured at attendance to the primary health care unit to the hospital, at start of treatment $\left(T_{0}\right)$ and then every 6 up to $72 \mathrm{~h}$. Parasite species was assessed in Giemsa-stained thin blood smears at admission. Parasite densities were estimated, in thick smears, by counting asexual parasites per 200 leucocytes. This was performed before admission and every 24 up to $72 \mathrm{~h}$. Out of 169 patients who participated in the study until $72 \mathrm{~h}$, samples from 104 patients, equally distributed between the four treatment groups ( 21 in each group), were randomly selected for cytokine analyses.

\subsection{Antibodies used for cytokine determination}

The following mouse antibodies against human cytokines were used as catcher antibodies: IL-4 (82.4), IL-6 (13A5), IL-10 (9D7), IL-12-I (p40 chain), IL-13I, IFN- $\gamma$ (1DIK) (MABTECH, Stockholm, Sweden), IL-1 $\beta$ (ILB1-H6) (Endogen, Woburn, MA, USA) and TNF- $\alpha$ (Mab1) (Pharmingen, San Diego, CA, USA). Biotinylated antibodies used for detection were: IL4 (12.1), IL-6 (39C3), IL-10 (12G8), IL-12-II (p40 chain), IL-13-II, IFN- $\gamma$ (7-B6-1) (MABTECH, Stockholm, Sweden), IL-1 $\beta$ (ILB1-H67) (Endogen, Woburn, MA, USA) and TNF- $\alpha$ (Mab11) (Pharmingen). Goat antibodies against human IL-18 (52713.11 and BAF 318) were purchased from R\&D systems (Abingdon, United Kingdom). Blocking antibodies were: mouse Ig (1DIK or 9D7) (MABTECH, Stockholm, Sweden) or normal goat IgG (AB-108-C).

\subsection{Cytokine determinations}

The cytokines were analysed by sandwich ELISAs. Briefly, half-area ELISA plates (Corning Incorporated, Corning, NY, USA) were coated over night at $4{ }^{\circ} \mathrm{C}$ with $25 \mu \mathrm{L}$ of catcher antibodies $(1 \mu \mathrm{g} / \mathrm{mL})$. Phosphate buffered saline (PBS) supplemented with $0.05 \%$ Bovine serum albumin was used for blocking ( $90 \mathrm{~min}$, at RT) and for dilution of standards and samples. To reassure specific binding, blocking antibodies were applied to the plates immediately before addition of the samples and standards. All test samples were coded and applied randomly in duplicates (diluted 1:1) into the pre-coated plates and incubated over night at $4{ }^{\circ} \mathrm{C}$. Bound cytokines were assayed using biotinylated cytokine specific antibodies (for $2 \mathrm{~h}$, at $37^{\circ} \mathrm{C}$ ), followed by alkaline phosphatase (ALP)-conjugated streptavidin (MABTECH, Stockholm, Sweden) diluted 1:1000 and incubated (90 min, at RT). Thereafter the phosphatase substrate (Sigma Diagnostics, St. Louis, MO, USA) was applied and the optical density was read at $450 \mathrm{~nm}$. Cytokine concentrations were calculated from standard curves obtained by incubating serial dilutions of the respective recombinant cytokines (NIBSC, Hertfordshire, United Kingdom or IL-18 from R\&D systems, Abingdon, United Kingdom). Standards were aliquoted and stored at $-70^{\circ} \mathrm{C}$. The detection limits were set according to the linear part of the standard curve and the background values of buffer controls and were for: IL-1 $\beta$ 3-3000, IL-4 10-3000, IL-6 30-10 000, IL-10 30-3000, IL-12 10-3000, IL-13 15-2000, IL-18 100-30 000, TNF- $\alpha$ $30-4000 \mathrm{pg} / \mathrm{mL}$ and IFN- $\gamma 0.01-30 \mathrm{U} / \mathrm{mL}$, respectively.

\subsection{Calculations and statistics analysis}

All correlations were analysed with the non-parametric Spearman rank order coefficient. In case of nondetectable levels a value of 1 (or 0.01 for IFN- $\gamma$ ) was used. Ratios were calculated by dividing the cytokine levels of two different cytokines. Comparison of plasma cytokine levels between treatment groups was analysed by Kruskal Wallis test for ranked median values. Comparisons between the cytokine levels at different time points were analysed by Friedman ANOVA and the post hoc test by Wilcoxon. Progression of cytokine responses in the different treatment groups was calculated by subtracting the values (plasma levels or ratios) at the second 
time point from the first and the differences between the treatment groups were compared by Kruskal Wallis test for ranked median values. Ratios in the different treatment groups at different time points were compared by Kruskal Wallis test for ranked medians. All statistical tests were two sided with a significance level of $p<0.05$. The Bonferroni correction is sometimes used when testing multiple variables, since the more associations that are studied, the greater likelihood of finding one that exists solely due to chance. A higher threshold for statistical significance is calculated by dividing the current threshold $(p=0.05)$ by the number of cytokines tested $((p=0.05) / 9)$, which gives $(p=0.006)$. The significance of this correction is disputed in some circumstances, but is included in the result part as a complement (Perneger, 1998).

\section{Results}

\subsection{Relationships between fever, parasitemia and plasma levels of cytokines}

Pre-treatment plasma levels and the frequencies of detection of the nine cytokines tested are presented in Table 1. Associations between cytokine levels, parasitemias and body temperatures are presented in Table 2 . Because of the fluctuations of the temperature over time, a mean value was calculated from the measurement before admittance and from that of start of treatment. Strongest associations were found between body temperature and IL-10, IFN- $\gamma$ and IL-6 (Table 2). Significant associations were also detected between parasitemia at day 0 and plasma levels of IL-6 and IL-10 (Table 2). On day 2, IL-10 and IL-6 levels still correlated with body temperature and IL-10 levels with parasitemia (Table 2).
Table 2

Cytokine levels correlate with fever and parasitemia day 0 and day 2

\begin{tabular}{|c|c|c|c|c|}
\hline \multirow[t]{2}{*}{ Cytokine } & \multicolumn{2}{|c|}{ Day 0} & \multicolumn{2}{|c|}{ Day 2} \\
\hline & $R$ & $p$-Level & $R$ & $p$-Level \\
\hline \multicolumn{5}{|c|}{ Temperature } \\
\hline IL-10 & 0.38 & $<0.001$ & 0.34 & $<0.001$ \\
\hline IFN- $\gamma$ & 0.25 & 0.009 & 0.11 & 0.3 \\
\hline IL-6 & 0.23 & 0.02 & 0.24 & 0.01 \\
\hline \multicolumn{5}{|c|}{ Parasitemia } \\
\hline IL-6 & 0.28 & 0.004 & 0.15 & 0.1 \\
\hline IL-10 & 0.23 & 0.02 & 0.35 & $<0.001$ \\
\hline
\end{tabular}

Spearman rank order correlations $(n=104)$.

If the Bonferroni correction is used for multiple variable testing this would change the threshold for statistical significance to $p=0.006$, which would render the association between temperature and IFN- $\gamma$ to borderlineand temperature-IL- 6 and parasitemia-IL-10 day 0 below statistical significance. However, the likelihood of false positive results because of multiple variable testing is low, since there is a statistical significant association between temperature and IL- 6 and parasitemia and IL10 , respectively, at both day 0 and day 2 .

\subsection{Effects of antimalarial treatment on plasma cytokine levels}

The median levels of the plasma cytokine levels did not differ between the treatment groups at the start of treatment or at day 2 or 3 . However, there were major inter-individual differences in cytokine levels. Different approaches were applied to analyse the effect of the treatments, but no significant differences between the treatment groups in the magnitude of changes in

Table 1

Frequencies and concentrations of cytokines obtained in plasma from 104 Tanzanian children during acute uncomplicated Plasmodium falciparum malaria infections

\begin{tabular}{|c|c|c|c|c|c|c|c|c|c|}
\hline \multirow[t]{2}{*}{ Cytokine } & \multicolumn{3}{|c|}{$\begin{array}{l}\text { Frequencies of detection } \\
\text { (number) }\end{array}$} & \multicolumn{3}{|c|}{$\begin{array}{l}\text { Median cytokine concentration } \\
\text { among all patients }(\mathrm{pg} / \mathrm{mL})^{\mathrm{a}}\end{array}$} & \multicolumn{3}{|c|}{$\begin{array}{l}\text { Median cytokine concentration among patients } \\
\text { with detectable cytokine levels }(\mathrm{pg} / \mathrm{mL})^{\mathrm{a}}\end{array}$} \\
\hline & $0^{\mathrm{b}}$ & $2^{b}$ & $3^{b}$ & $0^{\mathrm{b}}$ & $2^{b}$ & $3^{b}$ & $0^{\mathrm{b}}$ & $2^{b}$ & $3^{b}$ \\
\hline IFN- $\gamma$ & 81 & 65 & 70 & 0.18 & 0.09 & 0.10 & 0.24 & 0.19 & 0.19 \\
\hline IL-10 & 104 & 100 & 94 & 500 & 200 & 120 & 500 & 200 & 160 \\
\hline IL-12 & 104 & 104 & 104 & 370 & 300 & 340 & 370 & 300 & 340 \\
\hline IL-13 & 51 & 42 & 47 & 0 & 0 & 0 & 120 & 120 & 140 \\
\hline IL-18 & 72 & 54 & 66 & 590 & 230 & 470 & 1000 & 750 & 920 \\
\hline IL-1 $\beta$ & 81 & 75 & 86 & 21 & 23 & 27 & 28 & 38 & 36 \\
\hline IL-4 & 62 & 52 & 60 & 165 & 0 & 13 & 29 & 28 & 32 \\
\hline IL-6 & 57 & 41 & 32 & 98 & 0 & 0 & 420 & 290 & 250 \\
\hline $\mathrm{TNF}-\alpha$ & 42 & 36 & 50 & 0 & 0 & 0 & 420 & 420 & 380 \\
\hline
\end{tabular}

\footnotetext{
${ }^{\text {a }} \mathrm{U} / \mathrm{mL}$ for IFN- $\gamma$.

b Day of measure.
} 
cytokine levels with time, or in the number of individuals with increasing/decreasing plasma levels between the time points were detected. A "balance" between pro-inflammatory and anti-inflammatory cytokines is thought to determine the outcome of disease. Ratios between the different cytokines did not differ between the treatment groups at any of the time points tested (not listed). Nor did changes in ratio values between the time points differ between the treatment groups (not listed).

\subsection{Kinetics of cytokine levels in plasma during treatment}

Data from all individuals were pooled for the kinetic analysis, since no differences were seen in cytokine levels between the treatment groups. From the start of the treatment $\left(T_{0}\right)$, the median levels of all tested cytokines, decreased significantly $(p<0.05$, ANOVA for repeated measure, Wilcoxon) up to day 2 , except for TNF- $\alpha$ and IL-1 $\beta$ for which no significant effect was found (Fig. 1). IL- 6 continued to fall from days 2 to $3(p<0.05)$ while IL-12, IL-13, IL-18 and IL-1 $\beta$ all increased $(p<0.05)$. Statistically significant net decreases in plasma levels from days 0 to 3 were seen for IFN- $\gamma$, IL-10, IL- 6 and IL-4.

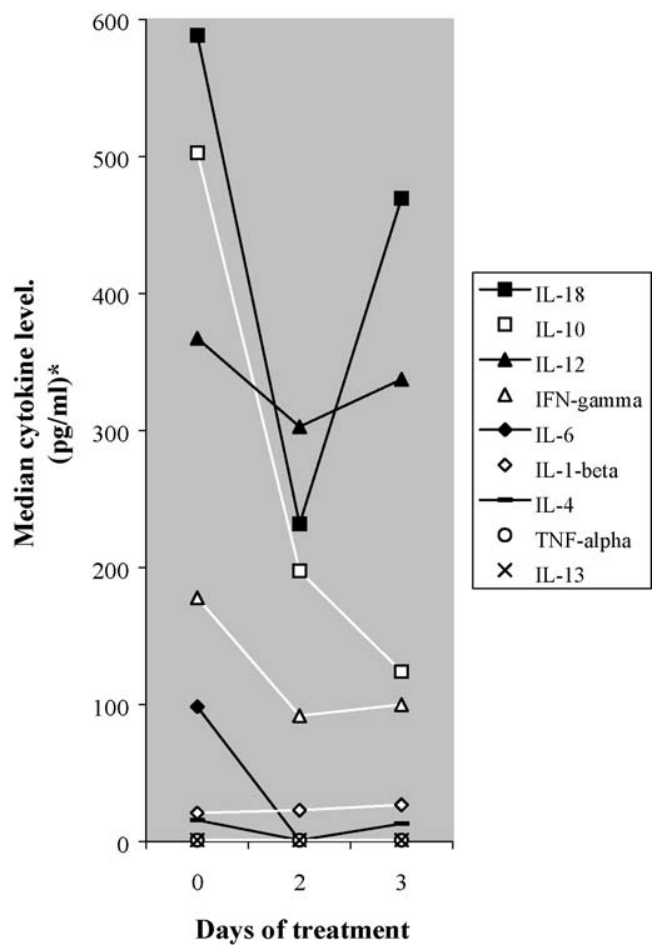

Fig. 1. Median cytokine levels during treatment of Plasmodium falciparum infection in 104 Tanzanian children.

\section{Discussion}

We hypothesised that chloroquine decreases fever and exhibit its anti-inflammatory effects by altering the levels and the balance of cytokine responses during malaria infections. However, despite significant associations between fever and plasma levels of several cytokines and clear antipyretic effects of chloroquine and paracetamol, no differences were detected in cytokine levels or ratios compared to those treated without antipyretics. The method of measuring of body temperature used here is somewhat imprecise. The result of this imprecision is that any associations with cytokine levels will be estimated conservatively. This form of variation around the 'true' temperature is not differential and cannot create a spurious association. The associations we report are therefore unlikely to be artefacts created due to imprecise temperature measurement. However, such imprecision may mask associations or will certainly reduce the statistical significance of true associations. Because we see corresponding associations at different time points between cytokine levels and temperature and parasitemia, respectively, we believe that it is unlikely that any of the associations listed appear solely by chance.

We found that before start of treatment, fever was positively associated with plasma levels of IL-10, IL-6 and IFN- $\gamma$. A positive association between fever and IFN- $\gamma$ has been determined in patients with $P$. vivax malaria (Brown et al., 1991; Seoh et al., 2003). IFN- $\gamma$ is not known to have direct pyretic effects but may contribute to fever via stimulation of IL- $1 \beta$ and TNF production in macrophages (Dinarello, 1999). IL-6 is best known for its systemic action on the liver, causing production of acute phase proteins and is also necessary for promoting the fever induced by TNF and IL-1, cytokines known to enhance the IL-6 production (Zetterstrom et al., 1998). The body temperature did, however not, correlate with TNF- $\alpha$ nor IL- $1 \beta$, which suggests that IFN- $\gamma$ and IL- 6 might be connected with fever independently of these cytokines in our patients.

In contrast to our findings, TNF- $\alpha$ levels have been shown to correlate with fever in several other studies (Grau et al., 1989; Mordmuller et al., 1997; Kwiatkowski et al., 1993; Karunaweera et al., 1992). The reason for this discrepancy may be that we studied children with uncomplicated $P$. falciparum malaria only, while others have included patients with severe disease or $P$. vivax. Stronger associations between fever and TNF in severe $P$. falciparum may result from generally higher and less fluctuating levels. Additionally, the severe disease manifestations might in turn contribute to the fever, thus amplifying the association. 
The positive association between the IL- 6 levels and parasitemia, indicates that the parasites perhaps could promote fever via induction of IL-6. The lack of correlation between IFN- $\gamma$ and parasitemia suggests that other factors than the parasite load are of importance for the production of IFN- $\gamma$ and for its association with fever. The importance of the host's degree of immunity for the production of IFN- $\gamma$ has been implied in in vitro studies using PBMC from individuals living in areas of different malaria endemicity (Rhee et al., 2001; Migot-Nabias et al., 1999). Thus, while there could be a causal relationship between parasite load and fever via the production of IL-6, the relationship between parasite load and fever with IFN- $\gamma$ seems more complex.

IL-10 is known to down regulate the production of pro-inflammatory cytokines like IL- $1 \beta$, TNF- $\alpha$, IL-6 and IL-12 (Moore et al., 2001) and to act as an endogenous antipyretic by lowering LPS-induced fever in mice (Leon et al., 1999). However, the positive correlation between body temperature and IL-10, IFN- $\gamma$ and IL- 6 in our study suggests a poor antipyretic effect or a limited ability of IL-10 to balance the production of these cytokines during malaria infection. Earlier studies show that production of higher levels of IL-10 is associated with less effective clearance of $P$. falciparum parasites (Hugosson et al., 2004; Jakobsen et al., 1996). It is also possible that IL-10 hinders the host's ability to clear parasites by suppressing antigen presentation and/or enhancing activation of regulatory $\mathrm{T}$ or $\mathrm{B}$ cells. The kinetics of the cytokine production in the present study revealed that the production of several cytokines, especially IL-1 $\beta$ and IL-12, increased in levels between days 2 and 3 of treatment. The reason for this is unknown but could perhaps be a consequence of a diminished suppressive effect by IL-10 when the levels of this cytokine decrease.

The fact that the cytokines that correlated with fever also decreased during treatment suggests that their subsequent production may somehow be related to the induction or the maintenance of the fever. However, the association could alternatively be explained by a common or parallel induction pathway for fever and pro-inflammatory cytokines. We have previously shown that lower mean temperatures $(6-48 \mathrm{~h})$ are achieved with $\mathrm{SP}+$ chloroquine and $\mathrm{SP}+$ paracetamol compared to SP alone or chloroquine alone (Hugosson et al., 2003). In this study we show that these differences were not reflected by differences in levels of any of the nine cytokines. The antipyretic effect of chloroquine was evident already after $6 \mathrm{~h}$ (Hugosson et al., 2003). A close kinetic study within that time interval might reveal if the antipyretic effect is connected with early changes in endopyrogenic cytokine levels or their downstream mediators. However, the slow decrease in body temperature in the group treated with SP alone indicates that whatever induces the fever, continues to do so even when the parasite mass is considerably reduced. The antipyretic effect of chloroquine therefore seems to be long lasting and thus potential chloroquine induced changes in cytokine levels should be expected to be seen also at later time points. The lack of differences in cytokine levels between the treatment groups could depend on too large individual differences among the patients in regard to genetics, maturity of the immune system, age, previous exposure to malaria, and other disease related differences. Another interpretation of the results is that chloroquine exerts its antipyretic effect at another level than on the production of the cytokines. Treatment with $\mathrm{SP}+$ paracetamol did not change the cytokine levels compared to SP alone. This is in line with that paracetamol is thought to suppresses the production of $\mathrm{PGE}_{2}$ by a mechanism downstream to cytokine production (Graham and Scott, 2005). Similar effects could be true for chloroquine.

It has recently been shown that chloroquine can inhibit signalling through TLRs (Lee et al., 2003; Zou et al., 2003). The vast product of malaria parasites, haemozoin, was shown to induce pro-inflammatory responses in dendritic cells via signalling through TLR9 (Coban et al., 2005). The inhibiting effect of chloroquine is specific for some TLRs and their differential distribution might explain the different effects of chloroquine on different cell types (Lee et al., 2003; Park et al., 2003). Chloroquine might therefore directly inhibit cytokine independent fever induction via TLRs (or other receptors) in the brain, while having no short turn effect on the plasma cytokine levels in uncomplicated $P$. falciparum malaria. Whether chloroquine's inhibiting effect on signalling pathways for TLRs has a clinical impact during human malaria infections still remains to be elucidated.

In conclusion, our data show associations between fever and plasma levels of IFN- $\gamma$, IL-10 and IL-6, while the antipyretic effects of chloroquine could not be explained by changes in production of these cytokines. However, further studies are needed to determine at what level in the inflammatory process chloroquine exerts its main anti-inflammatory and antipyretic effects.

\section{Acknowledgements}

We would like to thank the children, their families and the staff at Kibaha Hospital for their participation in this study. We thank Donath Tarimo, Fredrick Kalokola, late Jeremiah Masunga and Anette Sundstedt for clinical and laboratory assistance in the hospital. The work 
was supported by Swedish International Development Co-operation Agency (SAREC), The Swedish Medical Research Council and Bergvall's Foundation.

\section{References}

Anstey, N.M., Weinberg, J.B., Hassanali, M.Y., Mwaikambo, E.D., Manyenga, D., Misukonis, M.A., Arnelle, D.R., Hollis, D., McDonald, M.I., Granger, D.L., 1996. Nitric oxide in Tanzanian children with malaria: inverse relationship between malaria severity and nitric oxide production/nitric oxide synthase type 2 expression. J. Exp. Med. 184, 557-567.

Brown, A.E., Teja-Isavadharm, P., Webster, H.K., 1991. Macrophage activation in vivax malaria: fever is associated with increased levels of neopterin and interferon-gamma. Parasite Immunol. 13, 673-679.

Chaisavaneeyakorn, S., Othoro, C., Shi, Y.P., Otieno, J., Chaiyaroj, S.C., Lal, A.A., Udhayakumar, V., 2003. Relationship between plasma interleukin-12 (IL-12) and IL-18 levels and severe malarial anemia in an area of holoendemicity in western Kenya. Clin. Diagn. Lab. Immunol. 10, 362-366.

Coban, C., Ishii, K.J., Kawai, T., Hemmi, H., Sato, S., Uematsu, S., Yamamoto, M., Takeuchi, O., Itagaki, S., Kumar, N., Horii, T., Akira, S., 2005. Toll-like receptor 9 mediates innate immune activation by the malaria pigment hemozoin. J. Exp. Med. 201, 19-25.

Dinarello, C.A., 1999. Cytokines as endogenous pyrogens. J. Infect. Dis. 179, S294-S304.

Dinarello, C.A., 2004. Infection, fever, and exogenous and endogenous pyrogens: some concepts have changed. J. Endotoxin Res. 10, 201-222.

Ertel, W., Morrison, M.H., Ayala, A., Chaudry, I.H., 1991. Chloroquine attenuates hemorrhagic shock-induced suppression of Kupffer cell antigen presentation and major histocompatibility complex class II antigen expression through blockade of tumor necrosis factor and prostaglandin release. Blood 78, 1781-1788.

Graham, G.G., Scott, K.F., 2005. Mechanism of action of paracetamol. Am. J. Ther. 12, 46-55.

Grau, G.E., Taylor, T.E., Molyneux, M.E., Wirima, J.J., Vassalli, P., Hommel, M., Lambert, P.H., 1989. Tumor necrosis factor and disease severity in children with falciparum malaria. N. Engl. J. Med. 320, 1586-1591.

Hong, Z., Jiang, Z., Liangxi, W., Guofu, D., Ping, L., Yongling, L., Wendong, P., Minghai, W., 2004. Chloroquine protects mice from challenge with $\mathrm{CpG}$ ODN and LPS by decreasing proinflammatory cytokine release. Int. Immunopharmacol. 4, 223-234.

Hugosson, E., Björkman, A., Troye-Blomberg, M., 2002. Chloroquine enhances the number of IL-10 producing cells and the expression of B7-2 and ICAM-1 in in vitro-cultured PBMC. Scand. J. Immunol. 55, 399-408.

Hugosson, E., Montgomery, S.M., Premji, Z., Troye-Blomberg, M., Björkman, A., 2004. Higher plasma levels of IL-10 are associated with less effective clearance of $P$. falciparum parasites during treatment. Parasite Immunol. 26, 111-117.

Hugosson, E., Tarimo, D., Troye-Blomberg, M., Montgomery, S.M., Premji, Z., Björkman, A., 2003. Antipyretic, parasitologic, and immunologic effects of combining sulfadoxine/pyrimethamine with chloroquine or paracetamol for treating uncomplicated Plasmodium falciparum malaria. Am. J. Trop. Med. Hyg. 69, 366-371.

Jakobsen, P.H., McKay, V., N'Jie, R., Olaleye, B.O., D'Alessandro, U., Bendtzen, K., Schousboe, I., Greenwood, B.M., 1996. Soluble products of inflammatory reactions are not induced in children with asymptomatic Plasmodium falciparum infections. Clin. Exp. Immunol. 105, 69-73.

Jeong, J.Y., Jue, D.M., 1997. Chloroquine inhibits processing of tumor necrosis factor in lipopolysaccharide-stimulated RAW 264.7 macrophages. J. Immunol. 158, 4901-4907.

Karres, I., Kremer, J.P., Dietl, I., Steckholzer, U., Jochum, M., Ertel, W., 1998. Chloroquine inhibits proinflammatory cytokine release into human whole blood. Am. J. Physiol. 274, R1058R1064.

Karunaweera, N.D., Grau, G.E., Gamage, P., Carter, R., Mendis, K.N., 1992. Dynamics of fever and serum levels of tumor necrosis factor are closely associated during clinical paroxysms in Plasmodium vivax malaria. Proc. Natl. Acad. Sci. U.S.A. 89, 3200-3203.

Kwiatkowski, D., Molyneux, M.E., Stephens, S., Curtis, N., Klein, N., Pointaire, P., Smit, M., Allan, R., Brewster, D.R., Grau, G.E., et al., 1993. Anti-TNF therapy inhibits fever in cerebral malaria. Q. J. Med. 86, 91-98.

Landewe, R.B., Miltenburg, A.M., Breedveld, F.C., Daha, M.R., Dijkmans, B.A., 1992. Cyclosporine and chloroquine synergistically inhibit the interferon-gamma production by CD4 positive and CD8 positive synovial $\mathrm{T}$ cell clones derived from a patient with rheumatoid arthritis. J. Rheumatol. 19, 1353-1357.

Lee, J., Chuang, T.H., Redecke, V., She, L., Pitha, P.M., Carson, D.A., Raz, E., Cottam, H.B., 2003. Molecular basis for the immunostimulatory activity of guanine nucleoside analogs: activation of Toll-like receptor 7. Proc. Natl. Acad. Sci. U.S.A. 100, 6646-6651 (Epub 2003 May 6648).

Leon, L.R., 2002. Invited review: cytokine regulation of fever: studies using gene knockout mice. J. Appl. Physiol. 92, 2648-2655.

Leon, L.R., Kozak, W., Rudolph, K., Kluger, M.J., 1999. An antipyretic role for interleukin-10 in LPS fever in mice. Am. J. Physiol. 276, R81-R89.

Migot-Nabias, F., Luty, A.J., Ringwald, P., Vaillant, M., Dubois, B., Renaut, A., Mayombo, R.J., Minh, T.N., Fievet, N., Mbessi, J.R., Millet, P., Deloron, P., 1999. Immune responses against Plasmodium falciparum asexual blood-stage antigens and disease susceptibility in Gabonese and Cameroonian children. Am. J. Trop. Med. Hyg. 61, 488-494.

Moore, K.W., de Waal Malefyt, R., Coffman, R.L., O'Garra, A., 2001. Interleukin-10 and the interleukin-10 receptor. Annu. Rev. Immunol. 19, 683-765.

Mordmuller, B.G., Metzger, W.G., Juillard, P., Brinkman, B.M., Verweij, C.L., Grau, G.E., Kremsner, P.G., 1997. Tumor necrosis factor in Plasmodium falciparum malaria: high plasma level is associated with fever, but high production capacity is associated with rapid fever clearance. Eur. Cytokine Netw. 8, 29-35.

Mshana, R.N., Boulandi, J., Mshana, N.M., Mayombo, J., Mendome, G., 1991. Cytokines in the pathogenesis of malaria: levels of IL-I beta, IL-4, IL-6, TNF-alpha and IFN-gamma in plasma of healthy individuals and malaria patients in a holoendemic area. J. Clin. Lab. Immunol. 34, 131-139.

Othoro, C., Lal, A.A., Nahlen, B., Koech, D., Orago, A.S., Udhayakumar, V., 1999. A low interleukin-10 tumor necrosis factor-alpha ratio is associated with malaria anemia in children residing in a holoendemic malaria region in western Kenya. J. Infect. Dis. 179, 279-282.

Park, J., Kwon, D., Choi, C., Oh, J.W., Benveniste, E.N., 2003. Chloroquine induces activation of nuclear factor-kappaB and subsequent expression of pro-inflammatory cytokines by human astroglial cells. J. Neurochem. 84, 1266-1274.

Perneger, T.V., 1998. What's wrong with Bonferroni adjustments. BMJ 316, 1236-1238. 
Picot, S., Peyron, F., Donadille, A., Vuillez, J.P., Barbe, G., AmbroiseThomas, P., 1993. Chloroquine-induced inhibition of the production of TNF, but not of IL-6, is affected by disruption of iron metabolism. Immunology 80, 127-133.

Rhee, M.S., Akanmori, B.D., Waterfall, M., Riley, E.M., 2001. Changes in cytokine production associated with acquired immunity to Plasmodium falciparum malaria. Clin. Exp. Immunol. 126, 503-510.

Schofield, L., Hackett, F., 1993. Signal transduction in host cells by a glycosylphosphatidylinositol toxin of malaria parasites. J. Exp. Med. 177, 145-153.

Seoh, J.Y., Khan, M., Park, S.H., Park, H.K., Shin, M.H., Ha, E.H., Lee, B.E., Yoo, K., Han, H.S., Oh, S., Wi, J.H., Hong, C.K., Oh, C.H., Kim, Y.A., Park, J.W., 2003. Serum cytokine profiles in patients with Plasmodium vivax malaria: a comparison between those who presented with and without hyperpyrexia. Am. J. Trop. Med. Hyg. 68, 102-106.

van den Borne, B.E., Dijkmans, B.A., de Rooij, H.H., le Cessie, S., Verweij, C.L., 1997. Chloroquine and hydroxychloroquine equally affect tumor necrosis factor-alpha, interleukin 6, and interferongamma production by peripheral blood mononuclear cells. J. Rheumatol. 24, 55-60.

Zetterstrom, M., Sundgren-Andersson, A.K., Ostlund, P., Bartfai, T., 1998. Delineation of the proinflammatory cytokine cascade in fever induction. Ann. N. Y. Acad. Sci. 856, 48-52.

Zou, W., Amcheslavsky, A., Bar-Shavit, Z., 2003. CpG oligodeoxynucleotides modulate the osteoclastogenic activity of osteoblasts via Toll-like receptor 9. J. Biol. Chem. 278, 16732-16740 (Epub 12003 February 16728). 